\title{
Measuring Child Poverty and Well-Being: a literature review
}

Keetie Roelen

Franziska Gassman

\author{
Working paper \\ MGSoG/2008/WP001
}

January 2008

Maastricht University

Maastricht Graduate School of Governance 


\section{Maastricht Graduate School of Governance}

The 'watch dog' role of the media, the impact of migration processes, health care access for children in developing countries, mitigation of the effects of Global Warming are typical examples of governance issues issues to be tackled at the base; issues to be solved by creating and implementing effective policy.

The Maastricht Graduate School of Governance, Maastricht University, prepares students to pave the road for innovative policy developments in Europe and the world today.

Our master's and $\mathrm{PhD}$ programmes train you in analysing, monitoring and evaluating public policy in order to strengthen democratic governance in domestic and international organisations. The School carefully crafts its training activities to give national and international organisations, scholars and professionals the tools needed to harness the strengths of changing organisations and solve today's challenges, and more importantly, the ones of tomorrow.

Authors

Keetie Roelen, PhD fellow

Maastricht Graduate School of Governance

Maastricht University

Email: keetie.roelen@governance.unimaas.nl

\section{Franziska Gassmann}

Maastricht School of Governance

Maastricht University

Email: franziska.gassmann@governance.unimaas.nl

\section{Mailing address}

Universiteit Maastricht

Maastricht Graduate School of Governance

P.O. Box 616

6200 MD Maastricht

The Netherlands

Visiting address

Kapoenstraat 2, $6211 \mathrm{KW}$ Maastricht

Phone: +31 433884650

Fax: +31433884864

Email: info-gov@governance.unimaas.nl 


\title{
Measuring Child Poverty and Well-Being: a literature review Keetie Roelen and Franziska Gassmann
}

\author{
January 2008 \\ Maastricht Graduate School of Governance
}

\begin{abstract}
- Abstract-
Due to the acknowledgment that children deserve special focus in poverty measurement, the measurement of child poverty and well-being has received increasing attention within the academic and policy arena. The dependence of children on their direct environment for the provision of basic needs, the childspecific requirements in terms of their basic needs and the request for specific information for the formulation of child-focused policies are important reasons calling for the development of child poverty approaches. A range of approaches has been developed in the last decade to meet the need for a measurement tool especially geared to capture children and internalize their specific needs. Each of these approaches differ with respect to their chosen identification mechanism, aggregation methodology and data requirements. Decisions made on all these elements involve a set of advantages and disadvantages and have consequences for the usefulness of the approach to serve a specific purpose or audience. This review provides a structural overview of the current state of literature on the measurement of child poverty and well-being. We conclude that there are no perfect approaches for the measurement of child poverty and that each approach is the result of a specific conceptual framework in accordance with the availability of resources.
\end{abstract}

Keywords: child poverty, poverty measurement 


\section{Introduction}

Child-focused poverty and well-being measurement has played and remains to play a marginal role in the overall poverty debate. It is widely acknowledged that a wide gap exists with respect to child-focused poverty definitions and measurements within the academic world as well as policy arena (e.g. Gordon et al. 2003a, Gordon et al. 2003b, Minujin et al., 2005). However, due to greater recognition of the importance of developing and employing child-specific poverty measures, a range of approaches and methods have been developed in the last decade. The promotion of children's rights and the ratification of the Convention on the Rights of the Child by almost all countries in the world in the early 1990's have put children higher up the agenda of the poverty debate. A number of efforts have taken place since to draw a picture of children's lives in the developed as well as developing world. These efforts have taken place erratically in various forms, ranging from global studies to small-scale reports. Nevertheless, this small array of experiences provides a valuable and crucial source of information for the development of future approaches to define and measure child poverty and well-being.

This paper presents a review of the current state of literature on child poverty and well-being measurement ${ }^{1}$ and aims to extract lessons learned to aid the future development of such approaches. We begin the paper by answering the question why the issue of child poverty deserves special attention. A number of reasons, wellrecognized within the existing literature, outline the importance of focusing on childspecific poverty measures apart from general poverty measures. Next, a broad overview of the existing literature is provided. This section discusses various aspects that characterize child poverty approaches. We discuss the field of child poverty measurement along their identification mechanisms, methods of aggregation, data requirements, advantages and disadvantages and their implementation to date. In terms of the identification methods employed, we find that child poverty approaches differ with respect to the degree of dimensionality and their unit of analysis. Moreover, the use of different aggregation methods results in different poverty measures that can roughly be categorized as child poverty count measures, child poverty index measures and holistic child poverty approaches. In the subsequent section, a number of approaches are discussed in detail along the lines of this categorization in order to highlight the approaches' specific characteristics. Finally, the paper is concluded with a summary and lessons learned.

\section{Why measure child poverty?}

Several reasons can be put forward for the importance of a child-focused approach towards poverty (e.g. Boyden, 2006, Gordon et al. 2003a, 2003b, Harpham et al., 2005, Minujin et al., 2005, Young Lives, 2001, Waddington, 2004). A first reason is that children are at a higher risk of poverty regardless of place and time. Children are largely dependent on their direct environment for the provision of their basic needs. Since they are not independent economic actors by themselves, they rely on the distribution of resources by their parents, household or community members. Childfocused poverty measures are crucial to provide information about this distribution and thus about poverty at the child-specific level (e.g. White, Leavy and Masters,

\footnotetext{
${ }^{1}$ In the remainder of this paper, we restrict ourselves to the use of the term child poverty as a representation of all terms used for the measurement of the fulfillment of the basic rights and needs of children. These terms can be formulated in a positive, e.g. well-being, as well negative manner, e.g. deprivation.
} 
2002). A second reason is that if children grow up in poverty, they are more likely to be poor in adulthood as well. Poverty often manifests itself as a vicious circle that children are trapped in from birth onwards. Reducing child-poverty as a short-term objective would thereby also reduce adult poverty in the long run (e.g. Corak, 2004, DWP, 2002). Further, children are differently affected by poverty than adults are since their basic human needs are different. Children have different dietary requirements, for example, and the role of education is vital during their stage of life (e.g. Waddington, 2004). A child-specific approach can highlight and emphasize those needs that are especially crucial for children and their development. Finally, a generally accepted and workable definition and measurement method of child poverty is an important tool for both academics and policy makers. It does not only offer the opportunity to get an insight into children's poverty status but also gives the possibility to formulate and monitor sound poverty reduction objectives, strategies and policies (e.g. Ben-Arieh, 2000, Corak, 2006). In sum, there is a strong foundation to support the claim for poverty definitions and measures that are specifically aimed towards children, taking into account their specific needs and living conditions.

\section{Overview of child poverty specific approaches}

For the purpose of presenting a structural overview of existing child poverty approaches, we put forward a number of characteristics of such approaches. We use two distinct characteristics of poverty measures, as spelled out by Sen $(1979,1982)$ as well as three other important aspects for the discussion of child poverty measures in this literature review. According to Sen $(1979,1982)$ poverty measures differ with respect to the identification of the poor and the aggregation methods used to combine information about the poor into an overall poverty measure. The first characteristic is concerned with distinguishing the poor from the non-poor while the second feature of poverty measures refers to the way in which individual-level information of the poor is combined into a summary statistic. In addition, we consider the data requirements, advantages and disadvantages and the practical use of the child poverty approaches. This section discusses how child poverty approaches can differ with respect to these characteristics and the consequences that might hold for their use and implementation.

\subsection{Identification}

Deciding on a mechanism to identify the poor in a specific society is one of the first steps inherent to the development of a poverty measure (Alkire and Foster, 2007). An important tool to separate the poor from the non-poor is the poverty line (Blank, 2007). A poverty line "sets a standard for what it means to be poor" (Banerjee, Bénabou and Mookherjee, 2006) and involves a choice on the resource base taken into account and the threshold determining the poverty line (Blank, 2007). The identification element is of great significance for child poverty. The identification mechanism decides in how far an approach is child-focused and captures child poverty. There is a long-standing debate on the identification question and, more specifically, about which resource measure or welfare indicator to use and where to set the threshold for general poverty measurement ${ }^{2}$. However, this debate is rather new when it comes to child-specific poverty approaches. Do we assess the situation of children's lives by looking at the income of the household that they live in and if so, what do we consider to be a proper cut-off point below which we consider the children poor? Or do we look beyond monetary resources and include issues like

\footnotetext{
${ }^{2}$ Widely cited authors on this heavily debated and publicized topic include Amartya Sen, Peter Townsend, Tony Atkinson and Martin Ravallion.
} 
education, health and nutrition? Also in this case, the question arises at what point we consider children to be poor or not. The answers to these questions imply decisions on the unit of analysis as well as the specific issues deemed relevant to capture children's well-being. These decisions are not only based on theoretical arguments or scientific judgment but also involve a degree of value judgments (Blank, 2007, Corak, 2005).

With respect to the unit of analysis, one needs to choose whether to analyze the child as a member of a household or as an individual unit. Some approaches take the first option, while others opt for the latter. Incorporating the child as main unit of analysis ensures that the approach is child-focused and measures the situation as it presents itself to children. Considering the child to be a member of a household takes the analysis back to household level and forces one to rely on assumptions for the assessment of poverty at the child level. There are theoretical and practical considerations to make a choice for either the child or household as unit of analysis. Some scholars belief that the household is the proper unit of analysis because children's basic needs are mostly provided by the household and equivalence scales provide a proper tool for considering intra-household distribution (Corak, 2005). Others feel that one should assess the actual situation the child finds him or herself in without relying on assumptions (Gordon et al., 2003). Practically, however, childspecific information is less available than household level information, especially in developing countries. The main source of information for poverty analyses are budget or living standards surveys, which pre-dominantly holds data at the household level (White and Masset, 2002, 2003)

The resource base for the measurement of child poverty refers to those aspects of children's lives that are deemed capable of identifying whether a child is poor or not. The resource base can range from a uni-dimensional to a more multidimensional measure, basing the identification solely on the aspect of income or one other dimension or, in contrast, on multiple dimensions. Poverty approaches can be said to differ in their degree of dimensionality when setting the poverty line and separating the poor from the non-poor children. The degree of dimensionality can be visualized on a continuum of dimensionality, ranging from measures only including a single dimension as their resource base to approaches using a multitude of dimensions that aim to capture the complexity of poverty.

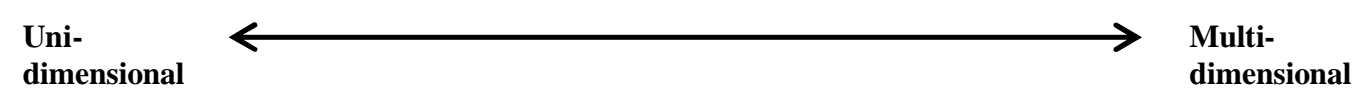

Figure 1 Continuum of dimensionality

Many have conveyed the need for a multidimensional approach to a poverty definition in general, and consequently for children, instead of a pure monetary or income-based definition. It is widely accepted that families and individuals are affected by many other aspects than only monetary resources (e.g. Minujin et al., 2005) and that income-based measures ${ }^{3}$ do not capture the non-monetary aspects of poverty (Waddington, 2004). A review of the current state of literature shows that a number of child poverty approaches adhere to the recognition of child poverty as a multidimensional concept while others work from a uni-dimensional perspective. The

\footnotetext{
${ }^{3}$ We use the term income-based measures to represent all monetary based measures, which could also be based on consumption or expenditures.
} 
child poverty approaches discussed in detail in the next section will be placed on the continuum of dimensionality to clarify their mechanism for the identification of poor children. As such, the continuum serves as a useful tool for categorizing the array of child poverty approaches in the current state of literature.

\subsection{Aggregation}

Once a method to separate the poor from the non-poor has been decided upon, the individual-level information needs to be combined to arrive at an overall poverty measure. A summary statistic providing information on the state of child poverty in a single figure is a strong tool for advocacy and communication as well as policy input and monitoring (Micklewright, 2001). The review of the existing child poverty approaches shows that they can roughly be divided in three categories on the basis of the aggregation methods used. These three categories are child poverty count measures, child poverty index measures and holistic child poverty approaches.

The child poverty count measures are those child poverty approaches that are based on individual level information. These measures "count" the number of poor children and provide a headcount of poverty or incidence rate. The count of poor children is performed by considering the number of children that find themselves below the poverty line, which is determined in the previous identification stage. Incidence measures can also be extended to measure the depth and severity of poverty. Information on the distance at which an individual child finds itself from the poverty line is aggregated to find how deep or how severe child poverty is ${ }^{4}$. A prerequisite for the calculation of a poverty count measure is the availability of micro-data. One needs information on the poverty status of individual children to be able to construct an overall poverty count, depth or severity indicator.

Child poverty index measures can be considered the second category of child poverty measures. It is an aggregate figure that enables one to compare the performance of various groups with respect to child poverty (Moore et al., 2007). These groups can comprise geographic locations (e.g. countries or states) or demographic groups (e.g. age groups or ethnic groups). A range of methods is available for the construction of index measures and inherent to this construction are decisions on the normalization, weighting and aggregation techniques (Nardo et al. 2005). On the basis of group index scores, the groups can consequently be ranked according to their performance. The Human Development Index (HDI) is an example of a poverty index measure, comparing country performance on the basis of educational attainment, longevity and standard of living (UNDP, 2007). Child poverty index measures can be based on micro- as well as macro-data. Information is required at the level of aggregation over which index scores are constructed. This can either consist of aggregated figures from micro-data or readily available macro-data figures. Due to the quantifiable output in summary statistics of both child poverty count and index measures, they are especially useful as monitoring and evaluation as well as communication tools.

A final category of child poverty measures that can be deducted from the existing range of approaches are the holistic child poverty measures. These approaches aim to capture more than simply the size of child poverty but also their causes and effects

\footnotetext{
${ }^{4}$ The poverty measure capturing the count of poor individuals is called the headcount, while the depth and severity of poverty are calculated with the use of the poverty gap and Foster-Greer-Thorbecke poverty measure. The methods of calculation and formal notations can be found in section 4.1.1 and Annex 2.
} 
and the many factors and processes at play. Ben-Arieh identifies that some approaches use "indicators that try to capture the whole complexity of the well being of children [..]" (Ben-Arieh, 2000). For these purposes, quantitative as well as qualitative information is combined to create an inclusive and holistic picture. The outcomes of this type of child poverty measure are less quantifiable and straightforward, making them less useful for policy monitoring or advocacy purposes, for example. By not oversimplifying the complex concept of child poverty, however, they provide useful insights and input into the debate on causes, effects and perceptions of child poverty.

\subsection{Data requirements}

The choices made with respect to the identification and aggregation methods for child poverty approaches have great consequences for the data requirements. Generally, data needs increase when a child poverty approach becomes more child-focused and incorporates more child-specific aspects. Hence, one could design an ideal child poverty approach in terms of identification and aggregation but will consequently be faced with constraints in terms of data availability. Approaches that consider the individual child as a unit of analysis require information at the child-level, which is more difficult and costly to collect than household-level data. An increase of the number of dimensions internalized in the child poverty approach also calls for more detailed information. Further, collecting data for certain domains might be more demanding than others. The collection of data on income or consumption patterns, for example, is a time-consuming and costly exercise. The aggregation methods chosen for the child poverty approach also have an impact the data needed for the actual calculations. Child poverty count measures require data on individual children, socalled micro data, for all domains included in the measure. If such information is not available, it is not possible to "count" the number of children that are below a poverty line. Child poverty index measures can be calculated on the basis of either micro or macro data as long as the information can be disaggregated down to the level of the groups that are to be compared. For example, when one wishes to compare child poverty index measures for all provinces within a specific country, data on the underlying dimensions can spring from different sources but all need to provide a representative figure at province level. Holistic child poverty approaches require a large range of information, including quantitative as well as qualitative data. Data from a large range of sources can be used make the picture on child poverty as inclusive as possible.

\subsection{Advantages and Disadvantages}

The in-depth account of a number of child poverty approaches in the next section will exhibit that all child poverty approaches have their advantages and disadvantages. These can lie in their theoretical design with respect to identification and aggregation or in their practical implications and ease of application. There is no such thing as a perfect approach for the measurement of child poverty. All poverty measures are subject to the trade-off of simple but practical measurement versus complex but more inclusive and informative measurement. Moreover, choices made in the process of developing a poverty approach are always subject to value judgments and a certain degree of ambiguity (Blank, 2007, Corak, 2005). While some scholars argue for one type of identification method with including a specific resource measure and cut-off point, others argue the opposite with similarly valid reasons. A child poverty approach is the end result of choices made with respect to identification and aggregation methods, in accordance with the availability of resources including data, time and budget. The advantages of the chosen approach thereby outweigh the disadvantages 
for those using the approach, ensuring that the purpose is served to the best extent possible. A systematic overview of the advantages and disadvantages of each approach can be found in Annex 1.

\subsection{Use of Child Poverty Approaches}

The actual use of the child poverty approaches ranges from those that have only been developed in theory without having been put in practice to those that are used and implemented internationally. The use of child poverty approaches is, on the one hand, a result of its practical feasibility and ease of application. On the other hand, it directly depends on the specific purpose that the approach serves (Ravallion, 1994). If an approach is designed to study child poverty from a specific angle it is less suitable for universal application. Further, the use of child poverty approaches is subject to overall trends with respect to child poverty measurement. Ben-Arieh (2000) identified a trend from a focus on survival to well-being in the formulation and thinking on child poverty and well-being indicators since the first State of the World's Children report by UNICEF in 1979. Instead of indicators emphasizing the mere survival of children, the focus shifted towards indicators of children's development and overall well-being (Ben-Arieh, 2000).

The categorization of child poverty approaches along the lines of their aggregation method is used to structure the next section. A number of child poverty approaches is discussed in detail to give an in-depth and comprehensive, but by no means exhaustive, overview of the existing efforts in child poverty measurement. For each child poverty approach, we discuss the approach's specific poverty definition, methodology, data requirements, advantages and disadvantages of its implementation and actual use to date. Further, each approach will be placed on the continuum of dimensionality as a tool to clarify the identification mechanism in place.

\section{Detailed review of child poverty approaches}

\subsection{Child Poverty Count Measures}

\subsubsection{Monetary Poverty Approach \\ Identification}

Monetary poverty, either based on income or consumption, conceptualizes child poverty as children living in low-income families or households. Low household income is considered to have a strong link with the well-being of children and their opportunities for development. The monetary poverty approach takes the household as the unit of analysis. The poor are identified by setting a poverty line on the basis of household income. Household income or monetary well-being reflects a single aspect of children's lives and the monetary poverty approach can as such be considered a uni-dimensional approach. Two main forms of poverty lines exist, namely absolute and relative poverty lines (Ravallion, 1994). An absolute poverty line is based on the ability to purchase a certain quantity of goods and services while a relative poverty line is related to the standard of living in the specific country (UNICEF, 2005). The identification of the poor according to the absolute poverty concept is most commonly based on a "basket" of goods and services that a household should be able to purchase (Corak, 2006). The cost of this basket determines the cut-off point for those households considered poor and those that are not. Both, low and middle income countries frequently determine two absolute poverty lines, one based on a minimum 
food basket identifying the extremely poor, and a slightly higher level adjusted for the consumption of other basic goods. As national standards are not appropriate for crosscountry comparisons, international absolute poverty lines, such as the one-dollar-perday poverty line ${ }^{5}$ have been widely used, also for the Millennium Development Goals (UN, 2007). Relative poverty lines are determined in the context of the time and place they are used and take into account the national standard of living (Save the Children, 2000). The line is set relative to this standard of living and shifts as the national level of well-being does. The Laeken Indicators for the EU define relative poverty lines at $50 \%$ and $60 \%$ of median income (European Commission, 2007), for example.

\section{Aggregation}

The monetary approach can be categorized among the child poverty count measures as it builds upon the count of the number of children in a household that find themselves below the poverty line. Standard poverty indicators within the monetary approach are poverty incidence (headcount), poverty gap and severity. In terms of poverty incidence, child poverty is the fraction of children in household falling below the poverty line as a percentage of all children (Ravallion, 1994). The poverty gap is obtained by multiplying the incidence rate with the shortfall of the poverty line to obtain a measure of the depth of child poverty (Ravallion, 1994, Deaton, 2006). Severity of child poverty can be assessed by a squared poverty gap measure, giving greater weigh to larger shortfalls from the poverty line (Ravallion, 1994, LokDessalien, 1999) ${ }^{6}$.

\section{Data Requirements}

Data requirements for calculating monetary (child) poverty are high. One needs information about the exact income or consumption pattern of a large number of households. The collection if this type of detailed information pre-dominantly occurs through a household budget or living standards surveys (Ravallion, 1994) but is timeconsuming and costly. Nevertheless, the majority of countries conduct such surveys as the monetary poverty measure is the most widely used method for poverty monitoring and analysis (Save the Children, 2000).

\section{Advantages and Disadvantages}

The main advantage of the use of monetary poverty concept is the quantifiable output. It does not only offer the opportunity to measure the incidence of poverty but also to quantify the depth and severity of poverty. The output consists of clear figures that can be used for national policy and poverty monitoring and international comparisons. Especially the poverty incidence and gap are appealing measures as they are wellknown and easily interpretable. The method also presents some clear disadvantages, though. Firstly, it is a one-dimensional measure of poverty, not including other dimensions that many experts call for. Secondly, the disaggregation from household to individual (child) level is based on strong assumptions. And thirdly, these methods all rely on household level data, which almost by definition do not cover some of the most vulnerable groups of children like orphans, abandoned children, children from illegal immigrants or street children (Waddington, 2004).

\footnotetext{
${ }^{5}$ The precise value is USD 1.08 per capita per day in 1993 USD values adjusted for PPP (www.unstats.un.org). Other absolute poverty lines used internationally are 2.15 USD PPP per capita per day, and 4.30 USD PPP per capita per day for middle-income countries.

${ }^{6}$ The technical notation of the aggregation methods used for the monetary poverty approach can be found in Annex 2.
} 
With respect to the second drawback mentioned, household budget surveys collect most information at household level. There is no information on the consumption of individual household members. In order to disentangle the aggregated (household) information for each individual in the sample unit, assumptions have to be made about the intra-household distribution. In the absence of information about individual consumption, most studies assume an equal distribution of household resources. To disaggregate the information to individuals within the household, there are mainly two choices. First, a simple method for making calculations down to the individual level is to divide total household income by the total number of household members, which is to use per capita income or expenditure (Deaton and Paxson, 1997, Minujin, et.al., 2002). This method disregards different needs of individuals living in a household (demographic composition) and economies of scale within the household (Deaton and Paxson, 1997, Gordon et al., 2003a, 2003b, Young Lives, 2001, Waddington, 2004). Secondly, another method often used is that of equivalence scales, which assume that a child costs or requires basic needs that are only a certain fraction of that for an adult and that larger households can benefit of economies of scale. Although this method clearly differentiates between the needs of adults versus that of children, it does not allow for differences among children due to age, gender or location and the choice of the scale is therefore often arbitrary.

\section{Use of the Monetary Poverty Measure}

The concept of monetary poverty is the most widely used measurement around the world with almost every country identifying its own national poverty line for the identification of poor households (Save the Children, 2000). The monetary poverty approach is used all over the world for poverty assessments, both nationally as well as internationally. Child poverty is a sub-category of the individual poverty rates, where poverty incidence is calculated for different population groups according to age and sex. In developing countries it has been widely recognized that the assessment of child poverty with this method does not tell the whole story about the (children's) situation. Monetary poverty assessments, providing a good first indication of the situation at hand, are often complemented with other measures and approaches to include other dimensions of poverty.

\subsubsection{Corak's Practical Approach \\ Identification}

In his work on child poverty measurement, Corak $(2005,2006)$ put forward a set of guiding principles for the development and use of child poverty approaches in public policy and provides a practical example by applying it to OECD countries. One of the purposes of the development of the practical approach towards child poverty by Corak $(2005,2006)$ is to "[...] take stock of child poverty and changes in child poverty in the majority of OECD countries since about 1990 when the Convention on the Rights of the Child came into effect" (Corak, 2005). The CRC is used as a starting point for the definition of poverty, thereby recognizing that child poverty is a multi-faceted phenomenon. Corak $(2005,2006)$ aims to incorporate the economic and statistical issues involved in the measurement of multidimensional poverty but by the same token stresses the role and importance of policy and political cycles. His six guiding principles for child poverty clearly emphasize that appropriate data and complex estimation methods can form a significant practical constraint for the use of child poverty approaches within the public policy arena. These principles are the following: 
1) Avoidance of unnecessary complexities: in rich countries, families are the primary provider of resources for children and therefore the use of an incomebased measure is good proxy;

2) Income measures alone do not capture all dimensions that poverty entail and should be complemented by indicators like health, nutrition and clothing and others. The number of complementary indicators, however, should be small and rather indicative than exhaustive;

3) Poverty lines should be drawn taking social norms and societal context into account;

4) Indicators should be updated regularly to allow for consistent monitoring of poverty and capture periods of high or low economic growth;

5) Employ a fixed and moving poverty line as backstop and target: during times of economic decline, the fixed line can be used as a backstop while during times of economic growth, the moving line serves as a new target;

6) Building of consensus public support for poverty reduction as value judgments are inherent to the definition and measurement of poverty;

While the first four principles deal with economic and statistical issues, the latter two are focused on the political and policy dimensions of poverty that are deemed equally important to the process of definition and measurement. On the basis of the guiding principles, Corak $(2005,2006)$ implies that the choice of indicators and consequent definition of poverty is in part guided by data availability and the avoidance of complexities. For Corak's analysis for OECD countries, this comes down to using a de facto income-based poverty line as the identification mechanism for child poverty. Explicitly emphasizing the practical and feasibility aspects of the approach transforms the approach from multidimensional in concept to uni-dimensional in implementation.

\section{Aggregation}

The child poverty measure within Corak's practical approach is a headcount poverty rate. The headcount refers to the proportion of children with equivalent incomes less than $50 \%$ of the national median equivalent income (Corak, 2006) ${ }^{7}$. Equivalent income is based on the assumptions that income is distributed equally within the household and the square root of household size is used as the equivalence scale. The use of equivalent incomes enables the child poverty measure to employ the individual child as the unit of analysis rather than the household. Corak (2006) tracks the performance of OECD countries over time by using both moving and fixed poverty lines.

\section{Data Requirements}

Although Corak's practical example compares countries within the OECD, the approach is initially geared towards national use rather than international comparison (Corak 2005, 2006). Hence, it is less stringent to use data from international databases or internationally comparative sources. As indicated above, the choice of indicators is largely data-driven as the emphasis is placed on the employment of easily collectable data that can be regularly updated. Since the approach predominantly focuses on poverty lines based on income or consumption, the main data requirement is accurate and reliable information on household income and expenditures patterns. Constraints with respect to the collection of information on household income and consumption are the same as discussed for the monetary poverty approach.

\footnotetext{
${ }^{7}$ The technical notation of the aggregation method used for Corak's practical approach can be found in Annex 2.
} 
Advantages and Disadvantages

The advantages and disadvantages of Corak's practical approach are similar as those discussed for the monetary approach as Corak's approach de facto resembles the monetary approach. Its main advantage, which is also Corak's main goal throughout his work, is its practical nature that makes the approach attractive to use for policy makers and analysts. The approach provides quantifiable output that is easily interpretable and useful for monitoring and evaluation purposes. Further, the six guiding principles leave room for complementing the monetary measure with other indicators to internalize other dimension of child poverty.

Use of Corak's Practical approach

Until now, Corak's approach has only explicitly been put into practice in the comparative study of OECD countries. However, the six guiding principles as formulated by Corak $(2005,2006)$ make the approach useful for national applications, taking into account the country-specific conditions and constraints. As its practical implementation is similar to the monetary measure, the approach might prove especially useful in revising the monetary approaches of individual countries along the lines of the six guiding principles.

\subsubsection{Bristol Deprivation approach}

Identification

The Bristol deprivation approach was developed to provide a first conceptualization of multidimensional child poverty in developing countries, making international comparisons possible but also feeds into the policy process. (Gordon 2003a). The deprivation approach fully recognizes the multiple dimensions of child poverty in its definition and methodology. From the CRC, Gordon et al. (2003a, 2003b) derive a number of basic needs that a child should have access to, converted into a series of deprivations when access is not available. The approach focuses on negative aspects of children's situations and will be referred to as the deprivation approach in the remaining of this paper. The human basic needs to which access is deemed crucial are:

1) food;

2) safe drinking water;

3) sanitation facilities;

4) healthcare facilities;

5) shelter;

6) education;

7) information.

These basic needs are represented in the deprivation approach as separate dimensions. The fulfillment of basic needs is assessed at the level of the individual child, considering the individual child as the unit of analysis. A continuum of deprivation is used within the deprivation approach to formulate operational definitions of deprivation within every dimension.

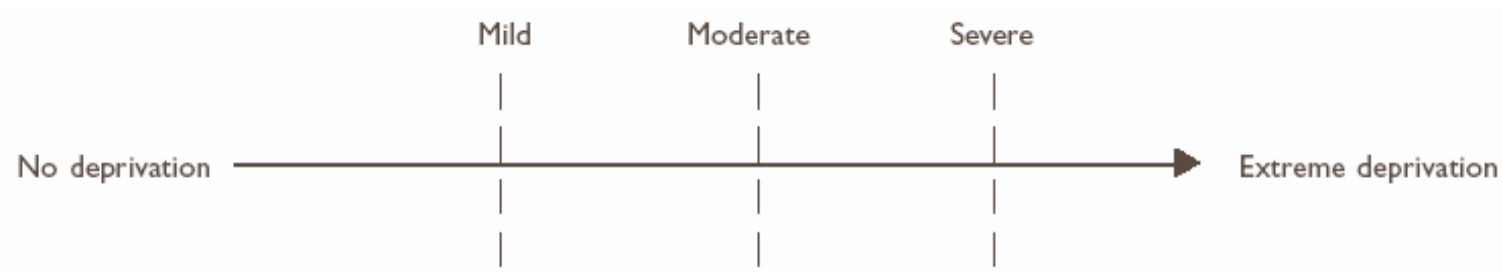

Figure 2

Source: Gordon et al., 2003a and 2003b 
Within every dimension, definitions for mild, moderate, severe and extreme deprivation are established. The cut-off point or poverty line is set at the severe deprivation definition within every dimension. If a child does not meet that criterium, it is considered deprived within that dimension. Within one dimension, more than one indicator can be identified to represent the cut-off point. Thresholds are set in such a way that they measure deprivation in conformation with internationally agreed standards and conventions but also subject to data availability and feasibility (Gordon et al., 2003a, 2003b).

\section{Aggregation}

The deprivation approach is a poverty count measure as it assesses for every child whether he or she is deprived in one or more dimensions. Consequently, a child can be considered to be severely deprived, absolutely poor or non-poor. A child is regarded dimension deprived when he or she does not meet the cut-off point of at least one of the indicators identified within that specific dimension. Consequently, severe deprivation is constituted by a child suffering deprivation within one or more of the dimensions. A child is considered to be living in absolute poverty if it suffers two or more severe deprivations. The output of the deprivation approach thus exists of deprivation counts for the seven dimensions as well as two aggregate poverty counts, being severe deprivation and absolute poverty. The approach taken for the calculation of the dimension deprivation is also known as the union approach (Atkinson, 2003 and Alkire and Foster, 2007). The union approach regards someone poor when deprived in at least one dimension. The intersection approach, on the other hand, considers an individual to be poor when deprived in all dimensions (Atkinson, 2003 and Alkire and Foster, 2007). The absolute poverty measure within the deprivation approach, assessing poverty on the basis of deprivation in at least two dimensions, is a so-called dual cutoff identification strategy (Alkire and Foster, 2007). The study as implemented by Gordon et. al (2003a, 2003b) limits itself to the assessment of child poverty incidence ${ }^{8}$. Delamonica and Minujin (2007) proposed a method to extend the analysis to the measurement of the depth and severity of child poverty by counting the number of deprivations that an individual child suffers.

\section{Data Requirements}

The indicators for the measurement of the severe deprivations can be collected from living standard household surveys, like the Demographic and Health Surveys (DHS) and the end-decade Multiple Indicator Cluster Survey (MICS2) on a national level. These surveys hold information at the household as well as individual level for issues in the areas of education, health, labor, shelter conditions and assets. The identification and aggregation methods of the approach require that information on all dimensions is available for each individual child. Hence, one has to rely on a single survey as a data source unless the same sample (with the same children) is used for other surveys so that information can be combined.

\section{Advantages and Disadvantages}

A clear advantage of the deprivation approach is the recognition of multidimensionality in child poverty and its straightforward way of conceptualizing this. It can be regarded as an absolute and simple measure of poverty as it compares to the headcount index. It defines severe deprivation or absolute poverty when a child

\footnotetext{
${ }^{8}$ The technical notation of the aggregation methods used for the deprivation approach can be found in Annex 2.
} 
is below a certain cut-off point set for a certain indicator and counts those children. Hence, the approach has the advantage of providing straightforward numbers in the various domains, which can be used to advocate progress or report deteriorations in fields of development. Moreover, the approach is versatile so that it can be easily adapted to data availability by formulating more or less domains. Another advantage of the deprivation approach is the possibility of analyzing overlaps of deprivation. Because the information springs from one source with information on different domains for all children, it is possible to assess the nature and combinations of deprivation.

The approach also has a number of disadvantages. Firstly, the approach relies on surveys, which almost by definition do not cover some of the most vulnerable groups of children like orphans, abandoned children, children from illegal immigrants or street children (Waddington, 2004). Children belonging to these vulnerable groups are simply not integrated into the sampling frame of these surveys, thereby most likely causing an underestimation of child poverty. Secondly, the analysis of overlap of deprivations as well as depth and severity of poverty is limited. Due to survey design and the fact that different issues are relevant for children at different ages, not all indicators and domains are observed for all children ${ }^{9}$. As a result, overlap can only analyzed for a few combinations of indicators or domains. Further, the count of deprivation to analyze the depth of severity of poverty would provide a biased picture as different numbers of deprivations can theoretically be observed for children in different age categories.

Use of the Bristol Deprivation approach

Gordon et al (2003a, 2003b) applied their approach to developing countries by using the wide range of data sets available on the national and international level. The countries were clustered and analyzed by region, namely East Asia, South Asia, Middle East, Sub-Saharan Africa and Latin America. The analysis is mostly comparative and does not go into large detail of the regions or individual countries. Developing countries can also use the deprivation approach and its indicators as a useful tool for monitoring the progress towards their MDG goals.

\subsection{Child Poverty Index Measures}

\subsubsection{EU Child Well-being Index}

Identification

Derived from the recognition that too little attention is paid to the children's wellbeing in Europe, Bradshaw et al. (2006) constructed a child well-being index to compare the $25 \mathrm{EU}$ Member States. Based on the CRC and other studies on the multidimensional nature of poverty, they formulated eight different clusters in which child poverty is analyzed. Conditions in these clusters are thought to have a strong impact on children's lives and well-being.

The clusters are as follows:

1) Material situation;

2) Housing;

3) Health;

\footnotetext{
${ }^{9}$ For example, anthropometric measures that are commonly used as indicators for proper nutrition are only observed for children up to 5 years of age in both the MICS and DHS. Indicators on education and child labor, however, are relevant and pre-dominantly measured for children above the age of 5 years. Hence, despite the fact that all indicators come from the same survey and sample, information on all indicators is not available for all children.
} 
4) Subjective well-being;

5) Education;

6) Children's relationships;

7) Civic participation;

8) Risk and safety.

Due to the acknowledgement of the importance of multiple dimensions for the assessment of children's well-being, the measure can be placed among the multidimensional child poverty approaches. Within these eight clusters, 23 domains and 51 indicators were identified. Although the choice for domains and indicators was initially made on the basis of the authors' multidimensional view on child poverty, it finally depended on the available data. Hence, Bradshaw et al. (2006) explicitly acknowledged the constraints faced in the implementation of an approach based on theory and expert opinion and adjusted its design accordingly. The output of the wellbeing index is a composite index for every EU Member State, summarizing the overall progress in the different clusters.

\section{Aggregation}

The EU child well-being index is a measure that compares the performance of EU member countries with respect to child well-being in relation to the average performance over all countries. An overall index score was calculated with the use of Z-scores ${ }^{10}$. Firstly, z-scores are calculated for each variable and averaged within every domain. Secondly, the z-score averages for the various domains are averaged for the eight clusters. Finally, the cluster z-score average is averaged to obtain the overall index score. If a country is performing above average, the index score will be greater than zero. A negative index score indicates that the specific country performed less than average. Working with $\mathrm{z}$-scores rather than mean ranks gives the advantage that not only rank orders are taken into account but also the degree of dispersion. Explicit weights were not assigned to indicators due to the arbitrariness of the decision. Zscores, however, hold an implicit weight on the basis of the degree of dispersion (Bradshaw et al., 2006).

\section{Data Requirements}

The choice of indicators and variables was to a certain extent data driven. The majority of the data was collected on a European or international rather than national level to avoid comparability problems. The databases used for the construction of the EU CWI index included World Development Indicators (WDI), Health Behaviour in School-aged Children (HBSC) database, OECD Programme for International Student Assessment (PISA), Eurostat, OECD Health Data, World Bank Health, Nutrition and Population Statistics (HNPStats), European Quality of Life Survey (EQLS), WHO Mortality Database, the European School Survey Project on Alcohol and Other Drugs (ESPAD) and Civic Education Study (CIVED). These data sources hold macro-data and provide information on specific indicators at the country level.

\section{Advantages and Disadvantages}

The advantages and disadvantages of using a composite index are clearly set out by Micklewright (2001) when discussing various possibilities for a measure of poverty and social exclusion for the UK. The main advantages of an index are the summary of various indicators in different domains it provides and the production of a single number that is easy to communicate. Both advantages make advocacy easier and can

\footnotetext{
${ }^{10}$ The technical notation of the construction of the EU Child Well-being Index can be found in Annex
} 
trigger public interest in the area of poverty. However, it is only useful in making comparisons between countries or between regions within a specific country, as the index score in itself does not carry much information. In case of the EU Index, the index does not provide information on progress towards the individual indicators as well as overall child well-being in absolute terms. Each country's performance is benchmarked against the overall average performance of all countries, notwithstanding the performance on an absolute scale. Furthermore, the strength of a one-number output is also its weakness. The upward and downward trends of different variables might compensate each other, not having an effect on the index. Hence, a lot of changes in the various clusters and domains might occur that are not observable for those only considering the overall output of the index.

Use of the EU Child Well-being Index

This specific index was used for the 25 EU Member Countries. A similar effort was conducted for CEE/CIS region in 2007 (Richardson, Hoelscher and Bradshaw, 2007). The index was constructed along the same lines as the EU index, using the structure of cluster, domains and separate indicators and aggregate these accordingly. To fit the context of this specific region, the clusters, domains and indicators were adjusted, giving the following list of indicators:

1) Material situation

2) Housing

3) Health

4) Education

5) Personal and social well-being

6) Family forms and care

7) Risk and safety

Within these 7 domains, 24 clusters and 52 indicators are identified to represent the areas of children's well-being, based on the data availability and regional CEE/CIS context.

\subsubsection{The US Child and Youth Well-being Index (CWI)}

\section{Identification}

The US Child and Youth Well-being Index (CWI) was developed by Land et al. (2001) to answer the question how well children and youths are faring in America. The index is designed to consider changes in child and youth well-being over time for specific demographic and geographical groups. The CWI aims to monitor children's well-being by state over time starting from the mid-70's up to the present. The underlying concept used for the construction of the index is based on the assessment of the quality of life, including objective as well subjective measures of well-being. Land et al. (2001) capture child well-being in seven different domains of life, based upon studies by Cummins (1996, 1997). Although these domains were originally designed to represent quality of life areas for the entire population, they are considered to capture the majority of areas of well-being for children. These domains include the following:

1) Material well-being;

2) Health;

3) Safety;

4) Productive activity;

5) Place in community;

6) Intimacy;

7) Emotional well-being. 
A number of 28 indicators are identified within the 7 dimensions of well-being. The annually published Key National Indicators of Child Well-Being (Federal Interagency Forum on Child and Family Statistics) and the data sources from which these indicators are drawn, served as a guide for the selection of these indicators. The index is constructed in such a way that it measures the performance over time relative to a specific base or reference year.

\section{Aggregation}

The percentage change from the base year value is averaged over the indicators within every domain and these domain indices are consequently averaged to obtain the overall index number. The domain index can be referred to as the equally-weighted domain-specific average index while the overall index is considered an equallyweighted components specific average index (Land, 2001) ${ }^{11}$. The indices can not only be calculated for an overall population but also be broken down by demographic categories like age groups and ethnicity to track their relative performances over time.

\section{Data Requirements}

The data requirements for the calculation of this index are quite extensive as information is required over time and on objective as well subjective issues. Indicators referring to subjective well-being are especially hard to collect as the majority of surveys incorporating these issues only include individuals above 18 years of age. However, as the purpose of the CWI focuses on tracking the performance over time of a few demographic groups (rather than at a low level of geographic disaggregation) many different information sources can be used with relatively little categorical breakdowns. The main data sources used for the CWI calculation in the US are the Annual Demographic Supplements to the March Current Population Surveys, data from the National Center for Health Statistics, the National Crime Victimization Survey, the High School Senior Survey and the National Assessment of Education Progress. Since the formulation of the Key National Indicators of Child Well-Being in 1997, 20 time series tracking child and youth well-being are also available (Land, 2001).

\section{Advantages and Disadvantages}

The large advantage of the US CWI is that it is a tool to measure the situation with respect to children's well-being over time. The majority of child poverty approaches focus on measurement at a specific point in time, comparing performances of different demographic and geographic groups. Further, as performance over time is measured in reference to a specific base year, the outcomes are easily interpretable and communicable. By the same token, the US CWI does not allow for any other analysis than tracking performance over time. The index scores do not provide information on how groups perform in relation to each other or an absolute level. Another downside of this tool is the large data requirement. To be able to measure performance over time in all 7 domains, one needs data about objective as well subjective aspects of well-being from a wide time range. These demanding data requirement will for many countries form a constraint in the implementation of such a CWI index. Moreover, inherent to the dynamic measurement of living standards is the issue of price corrections and changes in overall standards of living (Land, 2001).

\footnotetext{
${ }^{11}$ The technical notation of the aggregation methods used for the US CWI approach can be found in Annex 2.
} 


\section{Use of the US CWI}

This specific Child and Youth Well-Being Index has only been used for the US. The index was also especially designed on the basis of data availability and within the context of the US. The implementation in other countries of such an index that tracks the performance of children's well-being over time for different demographic groups requires adaptations to the national context and availability of information in that specific country.

\subsection{Holistic Child Poverty Measures}

\subsubsection{Young Lives Approach}

Identification

The Young Lives project aims at long-term qualitative and quantitative research to investigate the changes in child poverty in four specific countries, Ethiopia, Peru, India and Vietnam. The project is an initiative of DFID and Save the Children, UK, started in 2001 and will run for 15 years. The definition of child poverty is based on the basic needs derived from the core themes of CRC and the livelihoods framework from DFID (Young Lives, 2001). Rather than formulating one definition of poverty, the project puts forward a holistic framework with six child-specific outcomes to provide indicators for the poverty status of children. The choice of these outcomes was made with the notion that child poverty is different from adult poverty and needs a redirected focus. These six outcomes are (Young Lives, 2001):

1) Nutritional status

2) Physical morbidity

3) Mental morbidity

4) Life skills (literacy, numeracy, work skills etc.)

5) Developmental stage for age

6) Perceptions of well-being and life chances

The last of these outcomes emphasizes the importance of participatory methods in the poverty mapping process to learn more about children's own opinion and perceptions of poverty and their own situation. This is directly derived from the CRC and the right of the child to be heard and the recognition that children themselves act as social agents (Boyden, 2006). The qualitative information gathered will supplement the mainly quantitative information on the first five outcomes. The Young Lives project approaches child poverty in an inclusive manner and wishes to capture the large array of processes (its causality), factors and forces that influence children's lives and child poverty. Furthermore, it does so in a longitudinal study over a period of 15 years. The analytical framework is presented by Boyden (2006) as follows: 


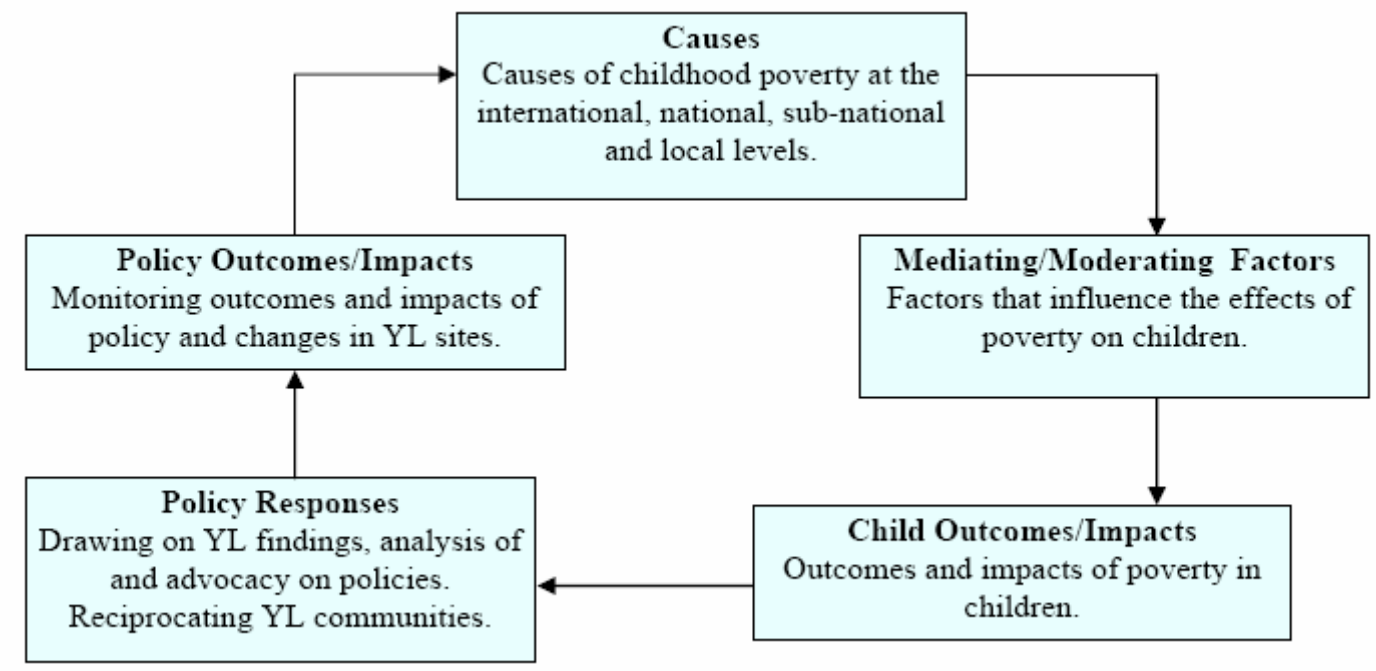

Figure 3

Source: Boyden, 2006

The approach aims to place outputs, outcomes and impacts in such a framework to display the complexity, causality and inter-linkages between the various factors that influence child poverty. It does not aim to produce a comprehensive set of indicators or a single poverty figure. Therefore, we can only provide an overview of the identification of the poor in the form of an analytical framework but not present a method of aggregation.

Data Requirements

The Young Lives project combines quantitative and qualitative data over a period of 15 years to be able to conduct longitudinal analysis. The collection of the data is part of the project and through, for example, participatory poverty assessments a wide array of information is collected.

Advantages and Disadvantages

The Young Lives approach provides a very holistic and inclusive method of not only child poverty or well-being but a whole child livelihood analysis. It describes inputs, outputs, outcomes and impacts related to child poverty and its policy processes, uses factual as well as subjective data and recognizes overlap in these issues. It does not attempt to simplify childhood well-being to a few indicators or aggregate measure or structure it in a cause and effect framework. To make such an inclusive analysis of child poverty, a large amount and specific data is needed that demands high national and local capacity for its collection.

By the same token, the inclusiveness and lack of quantifiable outcome also makes the approach less easy to use for dissemination and advocacy purposes. It is difficult to summarize the analysis into one main message about children's well-being and to raise public awareness. Moreover, the lack of quantifiable output on a regular basis makes the approach less appropriate for regular monitoring of policy and child poverty.

Use of Young Lives Approach

Countries that are currently involved in the Young Lives project and take part in the 15-year longitudinal study are India, Peru, Ethiopia and Vietnam. These countries were chosen for its different development context they find themselves in (Young Lives, 2001). Peru can be considered as the most developed country in the study, 
Ethiopia is a highly indebted country that experienced in decline in development in the last decade, India's state of Andra Pradesh is undergoing processes of liberalization and privatizations while Vietnam is experiencing rapid growth coming from a former centrally planned economy (Young Lives, 2006).

\subsubsection{DEV Framework for Child Poverty}

The Christian Children's Fund (CCF) started a comprehensive study in 2002 on experiences and impact of poverty on children (Feeny and Boyden, 2003). To incorporate the holistic and complex nature of poverty that was recognized throughout the study into a comprehensive approach, the DEV (Deprivation, Exclusion, Vulnerability) framework was developed. Its main purpose is to assist CCF staff and other stakeholders in deepening their understanding of child poverty and its related issues. The DEV framework is built up around three dimensions: deprivation, exclusion and vulnerability. Wordsworth, McPeak and Feeny (2005) emphasize that the use of these dimensions aims to demonstrate the complexity of child poverty and distance themselves from thinking in a cause and effect approach. The Deprivation dimension focuses on the lack of basic needs including food, shelter, and safe drinking water, among others. In addition to merely recognizing whether a child suffers certain deprivations, the elaboration on the severity, intensity and the context of the deprivations also receives emphasis. The Exclusion dimension considers the processes that prevent a child from fully participating in society. Four types of exclusion are identified: social status, group membership, economic status and cultural biases. The Vulnerability dimension refers to the dynamic nature of poverty and the external and internal threats and risk management that cause a child to fall into or escape poverty. As said above, the approach offers a conceptual framework that goes beyond the deprivation approach of Gordon et al. but has not been further developed into a tool for child poverty analysis and measurement. The latter is largely the result of criticism on the high emphasis that the majority of child poverty literature places on statistics and quantifiable situations. Feeny and Boyden (2003) belief this undermines the complexity of poverty and the experiences of children themselves.

\subsection{Continuum of Dimensionality}

On the basis of the in-depth discussions on the individual child poverty approaches, we can present them on the continuum of dimensionality on the basis of the identification mechanisms in place.

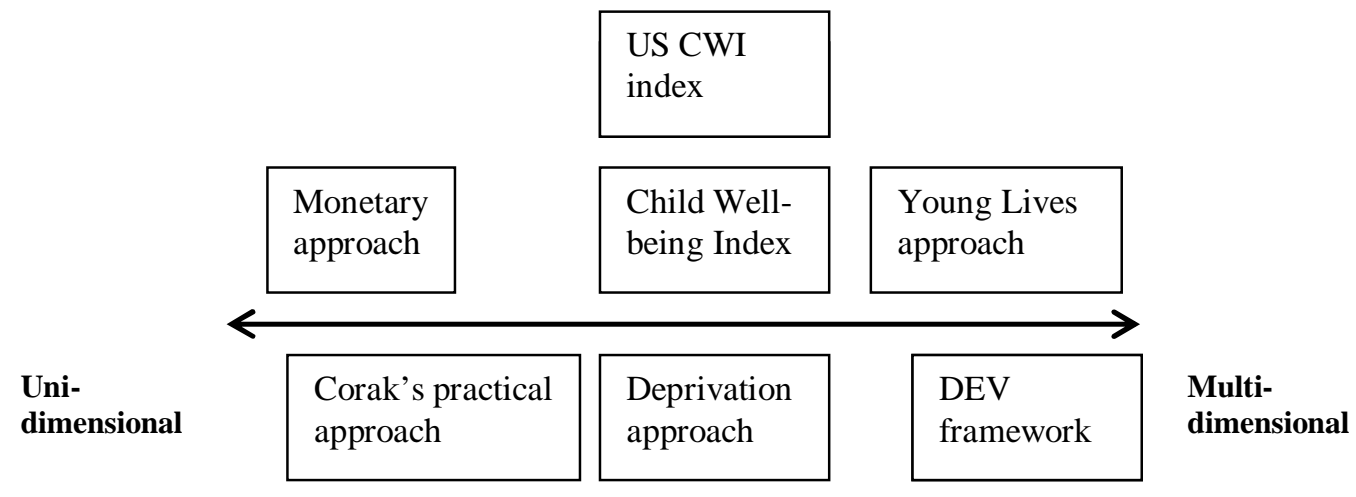

Figure 4 Continuum of dimensionality 
Figure 2 displays that the monetary approach is most uni-dimensional, followed by Corak's practical approach. The latter is uni-dimensional in de facto implementation but leaves room for the internationalization of other dimensions of poverty in concept. The deprivation approach, EU Well-being Index and US CWI index can be placed on the middle of the continuum. These approaches are multidimensional in concept as well as implementation but only provide quantifiable output. The Young Lives approach and DEV framework can be considered under the category of holistic and inclusive approaches. They recognize the complexity of child poverty in concept and do not simplify the situation by presenting the situation in a set of indicators.

\section{Conclusion}

The general overview and detailed account of existing child poverty approaches shows that child poverty approaches come in many different shapes and forms. To a certain degree, decisions made with respect to the development of child poverty measures are similar to those inherent to the development of any measure. The identification and aggregation methods are crucial elements of all measures that aim to visualize poverty, regardless of the specific group that the measure focuses on. For child poverty approaches, however, the vital issue with respect to these methods is how to capture children and child-specific issues by means of the poverty measure. The dependence of children on their direct environment for the provision of basic needs, the child-specific requirements in terms of basic needs and the need for specific information for the formulation of child-focused policies are important reasons that call for the development of child poverty approaches.

The current state of literature on child poverty approaches was discussed along the lines of a number of characteristics, being identification, aggregation, data requirements, advantages and disadvantages and the implementation to date of child poverty approaches. The identification element lies at the basis of a child poverty approach and is constitutive of the extent to which the approach captures children and child-specific issues. The method of aggregation for the construction of a poverty figure is determinant of how the state of child poverty is compiled into a summary statistic or set of poverty indicators. These two aspects, identification and aggregation, can be decided upon when developing a child poverty approach on the basis of theoretical ideas and assumptions. Considerations taken into account in the formulation of identification and aggregation methods involve the unit of analysis, the degree of dimensionality, the measure's accuracy, the complexity of its calculation and its impact on the academic and policy debate.

Decisions made on all these aspects involve a set of advantages and disadvantages in comparison to their alternative. From the review of the current state of literature, we can conclude that there are no perfect approaches for the measurement of child poverty. During the development of a child poverty approach, a careful assessment is made of the advantages and disadvantages of choices made for specific elements. The end result is an approach whereby the advantages of the chosen approach outweigh the disadvantages for those using the approach, ensuring that its specific purpose and audience is served to the best extent possible. For example, we find that a great disadvantage of the US CWI measure is its limited provision of information and useful only for tracking the performance of demographic and geographical groups over time, in reference to a base year. However, the main purpose of the development of this approach was exactly to provide insight into these dynamics over time. This 
confirms an argument that is not new but still highly relevant, which states that a poverty approach is to be designed and implemented in the light of its specific purpose.

Further, child poverty measures are subject to the trade-off of simple but practical measurement versus complex but more informative measurement. The review shows that the count and index approaches with quantifiable indicators as output are useful tools for policy monitoring and evaluation as well as advocacy and communication but only provide one part of the picture. The holistic and inclusive poverty measures, on the other hand, do not attempt to simplify the concept of child poverty but as a consequence do not provide clear measures of child poverty.

A final issue that became apparent throughout the review is the balance that needs to be found between theoretical and conceptual frameworks and the transformation of these in feasible and manageable approaches. The actual operationalization of a child poverty approach crucially depends on the (lack of) availability or resources including data, time and budget. The process of moving from an ideal to feasible child poverty approach was explicitly mentioned in the discussion of Corak's practical approach. Although not specifically outlined for the other approaches discussed in this review, it is an implicit process that all approaches are subject to. Here, the challenge lies in striking a balance between developing an approach driven by its constraints and one that is based on purely ideal theoretical arguments. 


\section{Bibliography}

Alkire, S. and J. Foster (2007). "Counting and Multidimensional Poverty Measurement", Oxford Poverty \& Human Development Initiative, OPHI, unpublished manuscript

Atkinson, A. B. (2003). "Multidimensional deprivation: contrasting social welfare and counting approaches." Journal of Economic Inequality 1: 51-65.

Ben-Arieh, A. (2000). "Beyond Welfare: measuring and monitoring the state of children - new trends and domains." Social Indicators Research 52: 235-257.

Blank, R. (2007). "Analyzing Poverty and Anti-Poverty Policies in the US and Other Higher-Income Nations", Maastricht Graduate School of Governance, Maastricht: PhD lecture

Boyden, Jo (2006) "Young Lives Project: Concepts and Analytical Framework", Young Lives, UK

Bradshaw, J., P. Hoelscher, et al. (2006). "An Index of Child Well-being in the European Union" Social Indicators Research 80(1): 133-177.

CHIP (2004). "Children and Poverty - some questions answered", CHIP Briefing, CHIP. London

Corak, M. (2005). "Principles and practicalities for measuring child poverty", Innocenti Working Paper, UNICEF

Corak, M. (2006a). "Do Poor Children become Poor Adults? Lessons from a Cross Country Comparison of Generational Earnings Mobility", Institute for the Study of Labor (IZA).

Corak, M. (2006b). "Principles and practicalities for measuring child poverty." International Social Security Review 29(2).

Cummins, R. A. (1996). "The Domains of Life Satisfaction: An Attempt to Order Chaos." Social Indicators Research 38: 303-328.

Cummins, R. A. (1997). "Assessing Quality of Life" in Quality of Life for Handicapped People, R. I. Brown (ed), Chapman \& Hall, London.

Deaton, A. (2006). "Measuring Poverty" in Understanding Poverty, A. V. Banerjee, R. Bénabou and D. Mookherjee (eds), Oxford University Press.

Delamonica, E. E. and A. Minujin (2007). "Incidence, Depth and Severity of Children in Poverty." Social Indicators Research 82: 361-374.

European Commission (2007). "Joint Report on Social Protection and Social Inclusion", Directorate-General for Employment Social Affairs and Equal Opportunities. Brussels.

Feeny, T. and J. Boyden (2003). "Children and Poverty: A Review of Contemporary Literature and Thought on Children and Poverty". Children and Poverty Series, Part I. Christian Children's Fund, CCF.

Gordon, D., S. Nandy, et al. (2003a). "The Distribution of Child Poverty in the Developing World" Bristol, UK, Centre for International Poverty Research.

Gordon, D., Nandy, S., Pantazis, C., Pemberton, S., and P. Townsend (2003b). Child Poverty in the Developing World. Bristol, Policy Press.

Land, K. (2005). "The Foundation for Child Development Index of Child Well-Being (CWI), 1975-2003 with Projections for 2004", Duke University, Durham, North Carolina.

Land, K., V. Lamb, et al. (2001). "Child and Youth Well-Being in the United States, 1975-1998: some findings from a new index." Social Indicators Research 56: 241-320.

Lok-Dessalien, R. (1999). "Review of Poverty Concepts and Indicators", UNDP. 
Micklewright, John (2001) "Should the UK government measure poverty and social exclusion with a composite index?", UNICEF Innocenti Research Centre, Florence

Nardo, M., M. Saisana, et al. (2005). "Handbook on Constructing Composite Indicators: Methodology and User Guide." OECD Statistics Working Papers $(2005 / 3)$.

Ravallion, M. (1994). Poverty Comparisons, Harwood Academic Publishers.

Sen, A. (1979). "Issues in the Measurement of Poverty." The Scandinavian Journal of Economics 81(2): 285-307.

Sen, A. (1982). Poverty and Famines: An Essay on Entitlement and Deprivation. Oxford, UK, Oxford University Press.

UN. (2007). "UN Millennium Development Goals." Retrieved 15-12, 2007, from http://www.un.org/millenniumgoals/\#.

UNDP. (2007). "Human Development Report." Retrieved 18-01-2008, 2008, from http://hdr.undp.org/en/.

UNICEF (2005). "Child Poverty in Rich Countries" Report Card. UNICEF Innocenti Research Centre. Florence.

Waddington, H. (2004). "Linking Economic Policy to Childhood Poverty: a review of the evidence on growth, trade reform and macroeconomic policy", $\underline{\mathrm{CHIP}}$ Report. CHIP.

White, H., J. Leavy, et al. (2002). "Comparative Perspectives on Child Poverty: A Review of Poverty Measures", Young Lives Working Paper 1 Young Lives.

White, H. and E. Masset (2002). Child Poverty in Vietnam: Using Adult Equivalence Scales to Estimate Income-Poverty for Different Age Groups. Young Lives Working Paper 6. Young Lives.

White, H. and E. Masset (2002). Constructing the Poverty Profile: An Illustration of the Importance of Allowing for Household Size and Composition in the Case of Vietnam. Young Lives Working Paper 3. Young Lives.

Young Lives. (2001). "Summary of the Young Lives Conceptual Framework." Retrieved 06-11, 2006, from www.younglives.org.uk

Young Lives. (2006). "An International Study of Childhood Poverty " Retrieved 0611, 2006, from www.younglives.org.uk. 


\section{Annex 1}

\section{Advantages and Disadvantages of Child Poverty Approaches}

\begin{tabular}{|c|c|c|c|}
\hline $\begin{array}{l}\text { Aggregation } \\
\text { method }\end{array}$ & $\begin{array}{l}\text { Child poverty } \\
\text { approach }\end{array}$ & Advantages & Disadvantages \\
\hline \multicolumn{4}{|l|}{$\begin{array}{l}\text { Child poverty } \\
\text { count } \\
\text { measures }\end{array}$} \\
\hline & Monetary poverty & $\begin{array}{l}\text { - quantifiable and easily } \\
\text { interpretable output }\end{array}$ & $\begin{array}{l}\text { - one-dimensional measure of } \\
\text { child poverty } \\
\text { - household as unit of analysis } \\
\text { - exclusion of vulnerable } \\
\text { groups not covered by } \\
\text { household surveys }\end{array}$ \\
\hline & $\begin{array}{l}\text { Corak's practical } \\
\text { approach }\end{array}$ & $\begin{array}{l}\text { - quantifiable and easily } \\
\text { interpretable output } \\
\text { - theoretically allows for } \\
\text { complementary, non- } \\
\text { monetary indicators }\end{array}$ & $\begin{array}{l}\text { - de facto one-dimensional } \\
\text { measure of child poverty } \\
\text { - exclusion of vulnerable } \\
\text { groups not covered by } \\
\text { household surveys }\end{array}$ \\
\hline & $\begin{array}{l}\text { Bristol deprivation } \\
\text { approach }\end{array}$ & $\begin{array}{l}\text { - multidimensional measure } \\
\text { of child poverty } \\
\text { - quantifiable and easily } \\
\text { interpretable output } \\
\text { - possibility to examine } \\
\text { overlaps in deprivation }\end{array}$ & $\begin{array}{l}\text { - exclusion of vulnerable } \\
\text { groups not covered by } \\
\text { household surveys } \\
\text { - problems in extension to } \\
\text { measure overlap, depth and } \\
\text { severity of poverty }\end{array}$ \\
\hline \multicolumn{4}{|l|}{$\begin{array}{l}\text { Child index } \\
\text { measures }\end{array}$} \\
\hline & $\begin{array}{l}\text { EU child well-being } \\
\text { approach }\end{array}$ & $\begin{array}{l}\text { - single summary indicator } \\
\text { for communication purposes } \\
\text { - method allows for } \\
\text { comparison of demographic } \\
\text { groups to average } \\
\text { performance }\end{array}$ & $\begin{array}{l}\text { - single summary indicator } \\
\text { hides underlying information } \\
\text { - method does not provide } \\
\text { information on improvements } \\
\text { in absolute terms }\end{array}$ \\
\hline & $\begin{array}{l}\text { US Child and youth } \\
\text { well-being index }\end{array}$ & $\begin{array}{l}\text { - single summary indicator } \\
\text { for communication purposes } \\
\text { - method allows for tracking } \\
\text { performance of demographic } \\
\text { groups over time }\end{array}$ & $\begin{array}{l}\text { - single summary indicator } \\
\text { hides underlying information } \\
\text { - method only allows for } \\
\text { comparison of demographic to } \\
\text { a reference year } \\
\text { - large data requirements }\end{array}$ \\
\hline \multicolumn{4}{|l|}{$\begin{array}{l}\text { Holistic child } \\
\text { poverty } \\
\text { approaches }\end{array}$} \\
\hline & Young Lives study & $\begin{array}{l}\text { - recognition of complex } \\
\text { nature of child poverty } \\
\text { - large range of information } \\
\text { collected }\end{array}$ & $\begin{array}{l}\text { - less useful for } \\
\text { communication or advocacy } \\
\text { purposes } \\
\text { - not appropriate for } \\
\text { monitoring purposes } \\
\end{array}$ \\
\hline & DEV framework & $\begin{array}{l}\text { - recognition of complex } \\
\text { nature of child poverty } \\
\text { - large range of information } \\
\text { collected }\end{array}$ & $\begin{array}{l}\text { - more difficult to } \\
\text { operationalize } \\
\text { - less useful for } \\
\text { communication or advocacy } \\
\text { purposes } \\
\text { - not appropriate for } \\
\text { monitoring purposes }\end{array}$ \\
\hline
\end{tabular}




\section{Annex 2}

\section{Technical notation of child poverty approaches}

Monetary Poverty Approach

The formal notations for the headcount index, poverty gap and poverty severity measure as presented below are taken from Ravallion (1994).

The headcount index denotes the proportion of the population with a monetary resource measure $y$ below a monetary poverty line $z$ :

$$
H=q / n
$$

where $H$ stands for the headcount index, $q$ represents the population below the poverty line and $n$ is the total population

The poverty gap is based upon the distance of the monetary resource of the unit of analysis (individual or household) to the monetary poverty line.

$$
P G=\sum_{i=1}^{q}\left(1-y_{i} / z\right) / n
$$

where $P G$ stands for the poverty gap, $i$ represents the unit of analysis (individual or household) and $y_{i}$ is the monetary resource of the unit of analysis $i$. As we are only considering the population below the poverty line $z, y_{i}$ is by definition lower than $z$.

The poverty severity can be measured by the Foster-Greer-Thorbecke measure, which gives larger weights to larger poverty gaps.

$$
F G T=\sum_{i=1}^{q}\left(1-y_{i} / z\right)^{2} / n
$$

where FGT stands for the Foster-Greer-Thorbecke measure (which can also be denoted as $\mathrm{P}_{2}$ ).

\section{Corak's Practical Approach}

Corak's practical approach can be denoted in the same manner as the headcount index for the monetary poverty approach. In this case, the poverty line $z$ is determined by $50 \%$ of the median income of the individual and resource measure $y$ stands for individual equivalized household income after taxes and transfers.

\section{Bristol Deprivation Approach}

The formal notation of the Deprivation approach below is taken from Roelen, Gassmann and De Neubourg (2007).

The percentage of children falling below the specified threshold per indicator is denoted as the indicator deprivation rate. 


$$
I V=\frac{\sum_{i=1}^{n} I_{i}}{n}
$$

where $n$ stands for all children for which the indicator is observable and $I_{i}$ represents a dichotomous variable with value 1 if the child is below the indicator threshold and thus vulnerable and value 0 if the child meets the threshold and is not vulnerable.

The domain deprivation rate reflects the rate of children experiencing deprivation within a specific domain as a percentage of children for whom the indicators within that domain are observable. The domain deprivation rate is given by

$$
D V=\frac{\sum_{i=1}^{n} D_{i}}{n}
$$

where $n$ represents all children for which the indicators are observable and $D_{i}$ stands for domain deprivation, a dichotomous variable with value 1 if the child suffers deprivation within the specific domain and value 0 if the child does not suffer deprivation. A child is considered to suffer domain vulnerability if it experiences indicator deprivation for at least one indicator within that domain:

$$
D_{i}=1 \quad \text { if } \sum_{i=1}^{d} I_{i} \geq 1
$$

where $d$ stands for the total number of indicators identified per domain.

The construction of the aggregate child poverty figures upon the domain deprivation. The rates for severe deprivation and absolute poverty can be written as follows:

$$
\begin{aligned}
& \text { SevDep }=\frac{\sum_{i=1}^{N} \operatorname{Sev}_{i}}{N} \\
& \text { AbsPov }=\frac{\sum_{i=1}^{N} A b s_{i}}{N}
\end{aligned}
$$

where $N$ represents the full sample size of children aged 0-16 and $\operatorname{Sev}_{i}$ and $A b s_{i}$ represent dichotomous variables with value 1 if a child suffers severe deprivation or absolute poverty:

$$
\begin{array}{ll}
\operatorname{Sev}_{i}=1 & \text { if } \sum_{i=1}^{D} D_{i} \geq 1 \\
A b s_{i}=1 & \text { if } \sum_{i=1}^{D} D_{i} \geq 2
\end{array}
$$

where $D$ stands for the total number of domains within the specific approach. 
EU Child Well-Being Index

Formally, the calculation of z-scores can be denoted as follows:

$$
z-\text { score }_{i}=\frac{x_{i}-\bar{x}_{i}}{\sigma_{i}}
$$

where $x_{i}$ represents the raw indicator value, $\bar{x}_{i}$ represents the average indicator value and $\sigma_{i}$ stands for the standard deviation. In other words, the use of z-scores converts indicators into a common scale with a mean of zero and standard deviation of one.

The domain index averages the z-scores for those indicators within a given domain.

$$
D I_{d}=\frac{\sum_{i=1}^{d} z-\text { score }_{i}}{d}
$$

where $D I_{d}$ stands for the domain index and $d$ is the number of indicators per domain.

The overall EU CWI is constructed by averaging the domain z-scores over all domains.

$$
E U I=\frac{\sum_{i=1}^{D} D I_{d}}{D}
$$

where EUI stands for the overall EU Child Well-being Index and $D$ represents all domains that are included in the CWI.

The US Child and Youth Well-being Index (CWI)

The formal notation for the US index is taken from Land (2001). The US CWI at time $t$ is a mean of percentage change rate ratios index and can be denoted as follows:

$$
U S C W I=\left(\frac{1}{N}\right) j\left(100+\left[\left(\frac{R_{i t}}{R_{i r}}\right) \times 100\right]\right)
$$

where $N$ denotes the number of basic indicators on which the index is based, $R_{i t}$ denotes the ith child and youth well-being indicator rate in the year $t>r, R_{i t}$ denotes the iit rate in the reference or base year $r$.

The equation is firstly applied to the basic child and youth well-being indicators to each indicator series within the well-being domains. Then the arithmetic average of the domain specific well-being indices is calculated to obtain an overall summary child and youth well-being index. This is termed the equally-weighted domainspecific average index. 


\section{Maastricht Graduate School of Governance Working Paper Series}

\section{List of publications}

\begin{tabular}{|c|c|c|}
\hline $\begin{array}{l}2006 \\
\text { No. }\end{array}$ & Author(s) & Title \\
\hline 001 & $\begin{array}{l}\text { Gassmann, F. and } \\
\text { G. Notten }\end{array}$ & $\begin{array}{l}\text { Size matters: Poverty reduction effects of means-tested and } \\
\text { universal child benefits in Russia }\end{array}$ \\
\hline 002 & $\begin{array}{l}\text { Hagen-Zanker, J. } \\
\text { and } \\
\text { M.R. Muñiz Castillo }\end{array}$ & $\begin{array}{l}\text { Exploring multi-dimensional wellbeing and remittances in } \\
\text { El Salvador }\end{array}$ \\
\hline 003 & Augsburg, B. & $\begin{array}{l}\text { Econometric evaluation of the SEWA Bank in India: } \\
\text { Applying matching techniques based on the propensity } \\
\text { score }\end{array}$ \\
\hline 004 & $\begin{array}{l}\text { Notten, G. and } \\
\text { D. de Crombrugghe ( }\end{array}$ & Poverty and consumption smoothing in Russia \\
\hline
\end{tabular}

\begin{tabular}{|c|c|c|}
\hline No. & Author $(s)$ & Title \\
\hline 001 & $\begin{array}{l}\text { Notten, G. and C. de } \\
\text { Neubourg }\end{array}$ & $\begin{array}{l}\text { Relative or absolute poverty in the US and EU? The battle } \\
\text { of the rates }\end{array}$ \\
\hline 002 & $\begin{array}{l}\text { Hodges, A. A. } \\
\text { Dufay, K. Dashdorj, } \\
\text { K.Y. Jong, T. } \\
\text { Mungun and U. } \\
\text { Budragchaa }\end{array}$ & $\begin{array}{l}\text { Child benefits and poverty reduction: Evidence from } \\
\text { Mongolia's Child Money Programme }\end{array}$ \\
\hline 003 & $\begin{array}{l}\text { Hagen-Zanker, J. } \\
\text { and Siegel, M. }\end{array}$ & The determinants of remittances: A review of the literature \\
\hline 004 & Notten, G. & $\begin{array}{l}\text { Managing risks: What Russian households do to smooth } \\
\text { consumption }\end{array}$ \\
\hline 005 & $\begin{array}{l}\text { Notten, G. and C. de } \\
\text { Neubourg }\end{array}$ & $\begin{array}{l}\text { Poverty in Europe and the USA: Exchanging official } \\
\text { measurement methods }\end{array}$ \\
\hline 006 & $\begin{array}{l}\text { Notten, G and C. de } \\
\text { Neubourg }\end{array}$ & $\begin{array}{l}\text { The policy relevance of absolute and relative poverty } \\
\text { headcounts: Whats in a number? }\end{array}$ \\
\hline 007 & $\begin{array}{l}\text { Hagen-Zanker, } J . \\
\text { and } M \text {. Siegel }\end{array}$ & $\begin{array}{l}\text { A critical discussion of the motivation to remit in Albania } \\
\text { and Moldova }\end{array}$ \\
\hline 008 & Wu, Treena & $\begin{array}{l}\text { Types of Households most vulnerable to physical and } \\
\text { economic threats: Case studies in Aceh after the Tsunami } \\
\text { (Theme 2) }\end{array}$ \\
\hline
\end{tabular}

\section{8}

\begin{tabular}{lll} 
No. & Author $(s)$ & Title \\
\hline 001 & $\begin{array}{l}\text { Roelen, K. and } \\
\text { Gassmann, F. }\end{array}$ & $\begin{array}{l}\text { Measuring Child Poverty and Well-Being: a literature } \\
\text { review }\end{array}$
\end{tabular}

